\title{
Magnocellular and Parvocellular Contributions to Responses in the Middle Temporal Visual Area (MT) of the Macaque Monkey
}

\author{
John H. R. Maunsell, Tara A. Nealey, and Derryl D. DePriest \\ Department of Physiology and Center for Visual Science, University of Rochester, Rochester, New York 14642
}

\begin{abstract}
Many lines of evidence suggest that the visual signals relayed through the magnocellular and parvocellular subdivisions of the primate dorsal LGN remain largely segregated through several levels of cortical processing. It has been suggested that this segregation persists through to the highest stages of the visual cortex, and that the pronounced differences beween the neuronal response properties in the parietal cortex and inferotemporal cortex may be attributed to differential contributions from magnocellular and parvocellular signals. We have examined this hypothesis directly by recording the responses of cortical neurons while selectively blocking responses in the magnocellular or parvocellular layers of the LGN. Responses were recorded from single units or multiunit clusters in the middle temporal visual area (MT), which is part of the pathway leading to parietal cortex and thought to receive primarily magnocellular inputs.

Responses in the MT were consistently reduced when the magnocellular subdivision of the LGN was inactivated. The reduction was almost always pronounced and often complete. In contrast, parvocellular block rarely produced striking changes in MT responses and typically had very little effect. Nevertheless, unequivocal parvocellular contributions could be demonstrated for a minority of MT responses. At a few MT sites, responses were recorded while magnocellular and parvocellular blocks were made simultaneously. Responses were essentially eliminated for all these paired blocks. These results provide direct evidence for segregation of magnocellular and parvocellular contributions in the extrastriate visual cortex and support the suggestion that these signals remain largely segregated through the highest levels of cortical processing.
\end{abstract}

The anatomical and physiological differences between the magnocellular and parvocellular subdivisions of the dorsal LGN are perhaps the most striking example of parallel organization in the primate visual system. These 2 classes of LGN neurons, together with their respective retinal ganglion cell inputs, comprise distinct subcortical channels of visual information. Although the functional contributions of the $\mathrm{P}$ channel and the $\mathrm{M}$ channel have been the subject of investigation for many ycars

Received Mar. 26, 1990; revised May 30, 1990; accepted May 30, 1990.

This research was supported by NIH Grant EY05911 and by an Alfred P. Sloan Fellowship to J.M. We wish to thank Ruth Anne Eatock, Vincent P. Ferrera, and William $\mathrm{H}$. Merigan for helpful comments on preliminary versions of the manuscript and Peter G. Vamvakias for excellent technical assistance.

Correspondence should be addressed to John. H. R. Maunsell, Department of Physiology, Box 642, University of Rochester, Rochester, NY 14642.

Copyright $@ 1990$ Society for Neuroscience $0270-6474 / 90 / 103323-12 \$ 03.00 / 0$ (see Lennie, 1980; Stone, 1983), recent observations have produced specific new proposals about their contributions to vision. In particular, it has become widely accepted that the $\mathrm{P}$ and $\mathrm{M}$ channels remain largely segregated in the cerebral cortex and account for many of the physiological differences seen between extrastriate visual areas.

Two discoveries in particular have contributed to this view. The first is the identification of anatomically and physiologically distinct cytochrome oxidase compartments in V1 (striate cortex; Wong-Riley and Carroll, 1984) and V2 of the macaque monkey and squirrel monkey (see Hendrickson, 1985). The existence of these compartments has encouraged the notion that the subcortical $\mathbf{P}$ and $\mathbf{M}$ channels remain largely segregated during the initial stages of extrastriate processing. The second discovery is that many areas in the later stages of cortical processing belong to 1 of 2 distinct processing pathways: a motion pathway, which includes much of the parietal cortex, and a color and form pathway, which includes most of the inferotemporal cortex (see Ungerleider and Mishkin, 1982; Mishkin et al., 1983; Van Essen and Maunsell, 1983; Van Essen, 1985; Maunsell and Newsome, 1987). The identification of these pathways and the recognition of their physiological differences has led to the hypothesis that neurons in the motion pathway are dominated by $M$ channel input, while the color and form pathway is driven primarily by the $\mathrm{P}$ channel. The evidence supporting this proposal has been reviewed in detail elsewhere (Livingstone and Hubel, 1987a, 1988; Maunsell, 1987; Maunsell and Newsome, 1987).

Although little conclusive evidence is available, numerous observations support this hypothesis. For example, recent behavioral studies have shown that animals with selective lesions of either the magnocellular or the parvocellular LGN are impaired on different types of visual tasks (Merigan et al., 1989a,b; Schiller et al., 1990). Another body of supporting observations includes the similarities between neuronal response properties in the subcortical P channel and the cortical areas of the color and form pathway and the similarities between those in the $M$ channel and the motion pathway. For example, several investigators have noted that most neurons in the motion pathway, like cells in the subcortical M channel, do not show pronounced color preferences (e.g., Zeki 1977; Robinson et al., 1978). In contrast, the sensitivity to color differences and specificity for complex forms that can be found in the later stages of the color and form pathway (see Desimone et al., 1985) are more consistent with $\mathrm{P}$ channel response properties, which include color opponency and sensitivity to high spatial frequencies. However, almost no investigations have directly compared response properties in the extrastriate visual cortex with those found in the subcortical $\mathrm{P}$ and $\mathrm{M}$ channels. 
Detailed physiological comparisons of response properties would be unlikely to establish the $P$ and $M$ channel contributions to extrastriate visual areas, in any case. While the distributions of $\mathrm{P}$ and $\mathrm{M}$ cell sensitivities differ for many stimulus dimensions, they overlap considerably (e.g., Derrington and Lennie, 1984). Furthermore, cortical processing could work to eliminate the differences between the 2 types of inputs. For example, the contrast sensitivity of neurons in the middle temporal visual area (MT) is greater than that of neurons in either the parvocellular or magnocellular layers of the LGN (Sclar et al., 1990). This enhanced sensitivity depends on summing inputs from many LGN neurons. While the contrast sensitivity of the subcortical M channel is greater than that of the P channel (Shapley and Kaplan, 1986), appropriate summation of signals from either channel could easily account for the sensitivity found in the MT. Because none of the other physiological differences found subcortically has been shown to be absolute, the existence of a particular response property in the cortex cannot be taken as conclusive evidence for input from 1 channel. Physiological approaches based on response latency (Maunsell and Schiller, 1984; Berson, 1985; Petersen et al., 1988) are similarly limited in that they can only provide conclusive evidence for contributions from the faster-conducting $\mathbf{M}$ channel input and cannot be used to rule out contributions from either channel.

Anatomical studies of the segregation of the $\mathrm{P}$ and $\mathrm{M}$ channels in the extrastriate cortex are similarly inconclusive. The neuroanatomical methods used to investigate the axonal connections linking different areas do not reveal the detailed circuitry of the connections. While connections between particular layers or cytochrome oxidase compartments in V1 and V2 appear to segregate different strcams of processing (sce Livingstonc and Hubel, 1988), substantial intermixing could occur. Even if only a small amount of intermixing occurred, it could have pronounced effects if it were repeated at each synaptic level or if it were enhanced through signals being repeatedly circulated in feedback loops. Subcortical connections could also contribute to intermixing. Every cortical visual area has abundant connections with subcortical structures (e.g., Graham et al., 1979; Graham, 1982; Tigges et al., 1982; Ungerleider et al., 1984). Subcortical afferents could mediate mixing of the $P$ and $M$ channels, thereby eliminating the segregation that is suggested by patterns of cortical connectivity.

Several observations argue against a segregation of $P$ and $M$ channel contributions in the extrastriate cortex. For example, physiological studies have shown that some intermixing occurs as early as the striate cortex (Malpeli et al., 1981). Anatomical connections betwecn visual arcas in the 2 different streams of processing also suggest that appreciable intermixing may occur (see Van Essen, 1985; DeYoe and Van Essen, 1988). In sum, the available evidence is sufficiently inconclusive that it would be consistent either with the $\mathrm{P}$ and $\mathrm{M}$ channels being the primary determinants of the differences between the temporal and parietal cortex, or with a complete intermixing between the channels in the first few levels of cortical processing.

We have looked more directly at the relationship between the subcortical $P$ and $M$ channels and cortical responses by examining their contributions to responses in the MT. Our approach has been to use selective inactivation of individual LGN layers. This technique, developed by Malpeli and Schiller (1979), involves measuring the strength of cortical responses during periods in which either the $P$ channel or the $M$ channel is blocked at the level of the LGN. By comparing the strength of cortical responses before and during the block, the contribution of the blocked channel can be inferred. Because this method measures a direct physiological effect of a block made at the level of the LGN, it avoids most of the problems of interpretation mentioned above.

We selected MT because it is the best candidate among primate cortical visual areas for receiving selective input. The primary recipient of the projection from the magnocellular layers of the LGN is layer 4C $\alpha$ in V1 (Hubel and Wiesel, 1972). This layer has strong connections with layer 4B (Lund and Boothe, 1975), which sends a direct projection to the MT (Lund et al., 1976; Maunsell and Van Essen, 1983b). The MT also receives projections from the thick cytochrome oxidase stripes in V2 (DeYoe and Van Essen, 1985; Shipp and Zeki, 1985) and V3 (Maunsell and Van Essen, 1983b), both of which also receive input from layer 4B in V1 (Burkhalter et al., 1986; Livingstone and Hubel, 1987b). M channel dominance in the MT is further suggested by several response properties of MT neurons: high contrast sensitivity (Sclar et al., 1990), short visual response latency (Maunsell, 1987), and a lack of pronounced color preference (Maunsell and Van Essen, 1983a; Zeki, 1974).

Using selective inactivation of LGN layers, we have found that the MT depends largely on the subcortical M channel for its excitatory drive, as predicted by the evidence cited above. However, we have also found a small but appreciable contribution from the $\mathrm{P}$ channel.

Preliminary reports of these data have been presented in abstract form (Maunsell et al., 1989; Nealey et al., 1989).

\section{Materials and Methods}

Preparation for recording. Data were collected from 10 hemispheres in 6 juvenile male macaque monkeys (5 Macaca fascicularis and $1 M$. mulatta) that weighed between 2 and $4 \mathrm{~kg}$. Each animal was initially dosed with ketamine $(15 \mathrm{mg} / \mathrm{kg}$ i.m.) and atropine $(0.01 \mathrm{mg} / \mathrm{kg}$ i.m.). Cannulae were then placed in a superficial vein and in the trachea, and the animal was positioned in a stereotaxic apparatus. Anesthesia was maintained during surgery and recording with sufentanil $(20 \mu \mathrm{g} / \mathrm{ml}$ i.v.). Craniotomies and durotomies were made dorsal to the LGN and the superior temporal sulcus. Microdrives were then positioned over these structures, and the cortex was covered with warm agar.

The animal was then paralyzed (vecuronium bromide, $50 \mu \mathrm{g} / \mathrm{kg}$ ) and respired with room air to maintain end-tidal $\mathrm{CO}_{2}$ near $32 \mathrm{~mm} \mathrm{Hg}$. Body temperature was regulated with a thermostatically controlled heating pad. Throughout the recording session (which lasted 60-150 hr), anesthesia and paralysis were maintained with a continuous intravenous infusion (sufentanil, $2 \mu \mathrm{g} / \mathrm{kg} / \mathrm{hr}$; vecuronium bromide, $100 \mu \mathrm{g} / \mathrm{kg} / \mathrm{hr}$ ), and the ECG, heart rate, end-tidal $\mathrm{CO}_{2}$, and rectal temperature were monitored. The adequacy of analgesia was confirmed by the absence of changes in heart rate in response to noxious stimulation. Cycloplegia and mydriasis were achieved with ophthalmic atropine (1\%). Gaspermeable contact lenses refracted the eyes onto a tangent screen 114 $\mathrm{cm}$ in front of the animal.

Recording and selective inactivation. For most experiments, recordings were made simultaneously from a microelectrode in the cortex and a recording/injection probe in the LGN. The microelectrodes were glassinsulated, etched Pt/Ir wires with impedances between 1 and $2 \mathrm{M} \Omega$ at $1 \mathrm{kHz}$. The recording/injection probes were based on the method of Malpeli and Schiller (1979) and were made from pulled glass pipettes that had their tips broken to leave an outer diameter of 25-50 $\mu \mathrm{m}$. An etched $\mathrm{Pt} / \mathrm{Ir}$ wire inside the glass extended $20-50 \mu \mathrm{m}$ beyond the tip. Each probe was filled with a solution containing a blocking agent (either $40 \mu \mathrm{M} \mathrm{Mg}{ }^{2+}$ or $2 \%$ lidocaine) that could be pressure injected from the tip. Signals from the probe in the LGN and from the microelectrode in the cortex were separately amplified, filtered, and monitored on an oscilloscope and speaker. Either single- or multiple-unit recordings were made from the cortex during data collection. Multiunit recording sites were separated by at least $250 \mu \mathrm{m}$. At each cortical site, a receptive field was plotted using a hand-held projector, and stimulus preferences were noted. The receptive field was then positioned on a video monitor using 


\section{LIDOCAINE INJECTIONS}

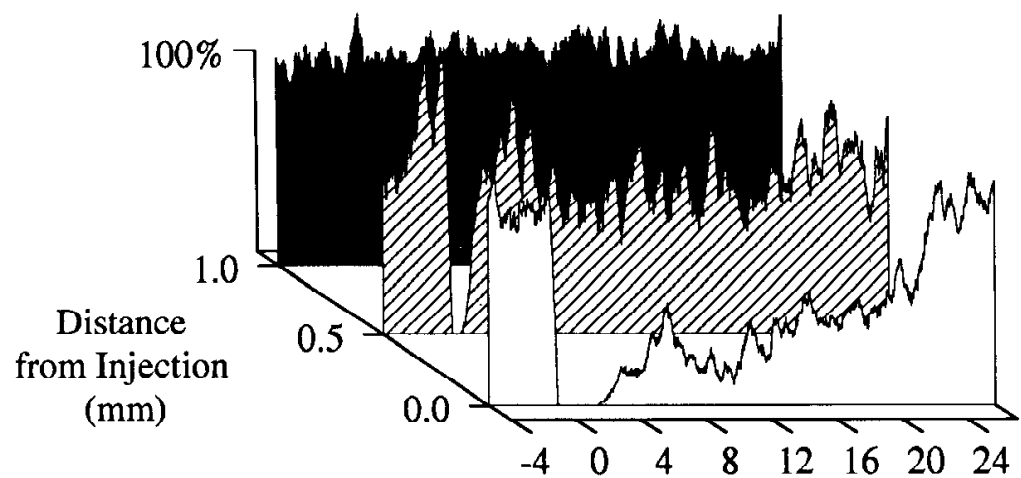

MAGNESIUM INJECTIONS

Time after Injection

(min)

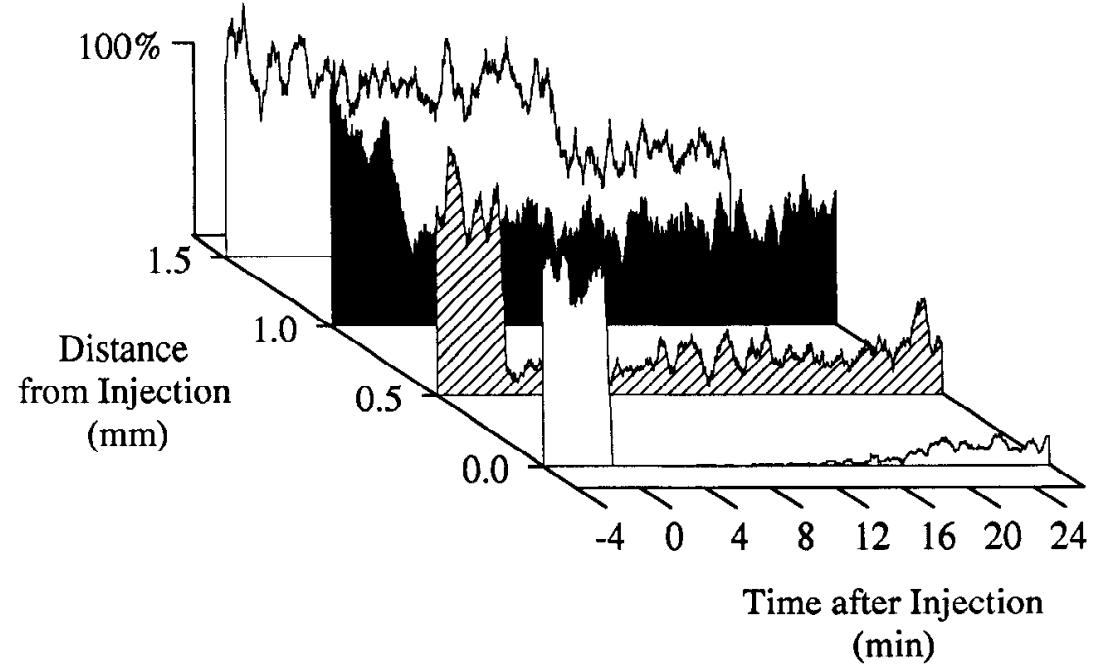

Figure 1. Spread of effects of 150-nl lidocaine and $\mathrm{Mg}^{2+}$ injections. The histograms represent responses recorded from sites within the LGN at different distances from an injection site. The horizontal axis represents time before and after the injection, and the vertical axis is the response, with each histogram normalized to its average level of response recorded during the $4 \mathrm{~min}$ immediately before the injection was made. The electrode and injection probe were aligned to $0.0 \mathrm{~mm}$ separation based on receptive field location and depth into a particular layer in the LGN. We estimate the accuracy of this method to be about $\pm 100 \mu \mathrm{m}$. Nonzero separations were achieved by advancing the recording electrode beyond the point of alignment. Effects of lidocaine injection are more localized and more reversible than those of $\mathrm{Mg}^{2+}$. a large mirror immediately in front of the animal. The video monitor ( $55 \mathrm{~Hz}$ frame rate) displayed bars or spots that could be moved under either joystick or computer control. All stimuli were white, were approximately $70 \mathrm{~cd} / \mathrm{m}^{2}$ on a background of $0.2 \mathrm{~cd} / \mathrm{m}^{2}$, and were very effective at driving both magnocellular and parvocellular neurons.

Once a cortical receptive field had been plotted, the recording/injection probe in the LGN was moved to a site that had a receptive field lying within the cortical field. The tip of the recording/injection probe could be unequivocally located in a particular LGN layer based on physiological criteria. These included the characteristic alternation of the driving eye from layer to layer and differences between the temporal frequency selectivities of magnocellular and parvocellular cells (Schiller and Malpeli, 1978). Once the probe was positioned, a localized reversible inactivation of the region was achieved by a pressure injection of a small quantity of either lidocaine, which blocks action potentials in both somata and axons, or $\mathrm{Mg}^{2+}$ in an isotonic saline solution. Magnesium blocks synaptic transmission by acting as an antagonist at voltage-dependent $\mathrm{Ca}^{2+}$ channels in presynaptic terminals (Dodge and $\mathrm{Ra}$ hamimoff, 1967) but does not appreciably affect voltage-dependent $\mathrm{Na}^{+}$ and $\mathrm{K}^{+}$channels that propagate action potentials in axons passing through the injected region (Hille, 1972). The amount injected was determined by measuring the movement of the meniscus within the glass probe through a microscope. The movement of the meniscus was calibrated, and controlled volumes as small as $25 \mathrm{nl}$ could be delivered. Injection volumes for both agents were in the range of 25-250 nl, with most injections between 50 and $150 \mathrm{nl}$.
The spread of inactivation from the injection center was determined in cxpcriments in which microelectrode recordings were made at different distances from injection sites in the LGN. The upper panel of Figure 1 shows responses to a flashing spot that were recorded in the LGN at different distances from 150-nl lidocaine injections. Responses near the center of the injection were abolished for more than 2 min and had recovered $30 \mathrm{~min}$ after the injection. At a distance of $0.5 \mathrm{~mm}$, activity was eliminated for approximately $1 \mathrm{~min}$, then quickly recovered. No effect was seen at a recording site $1 \mathrm{~mm}$ from an injection. The lower panel in Figure 1 shows corresponding data collected using $150-\mathrm{nl} \mathrm{Mg}{ }^{2+}$ injections. Magnesium differed from lidocaine in that its effects were only partially reversible. Recordings continuing for over 1 $\mathrm{hr}$ after injection (not shown) showed no further recovery beyond that which occurred in the first $0.5 \mathrm{hr}$. Magnesium injections also affected more distant sites than lidocaine injections of the same size. The responses recorded $1.5 \mathrm{~mm}$ from an injection site were unaffected for about $15 \mathrm{~min}$, but then dropped markedly.

In a few experiments, we also checked that blocking agents did not spread between LGN subdivisions by making injections in the parvocellular subdivision of the LGN while recording simultaneously from corresponding visual field representations in both the MT and the noninjected magnocellular subdivision. These recordings confirmed that the effects of the blocking agent were confined to the region of the injected layer (see Results).

Magnesium injections were used for experiments in 5 hemispheres because blockade reversal is not essential to demonstrate LGN contri- 
Figure 2. Effects of magnocellular LGN block on responses in MT. The left panel shows responses of a multiunit MT site before (Pre), during ( $I n$ $j e c t$ ), and after (Post) $85 \mathrm{nl}$ lidocaine were injected into layer 1 in the LGN. Time increases downward, with each horizontal raster line representing 1 stimulus cycle. In this case, each stimulus cycle lasted $630 \mathrm{msec}$ and consisted of movement back and forth along the preferred axis, as indicated by the line below the raster. The solid bar on the right side of the raster marks the period during which the injection was made. The response of the unit stopped abruptly when the injection was made. The right panels show smoothed average histograms of responses collected immediately before and after the injection period. Each contains 50 stimulus cycles, taken from the periods marked with open bars on the right of the raster display (left panel). The vertical axes are scaled in spikes/sec, and solid and open triangles mark the peaks and troughs in the histograms. The magnocellular block essentially abolished the MT response. The preinjection response (peak trough minus the background peak/ trough difference) was 49.2 spikes $/ \mathrm{sec}$, while postinjection response was -7.6 spikes/sec, yielding a blocking index of 1.15 .
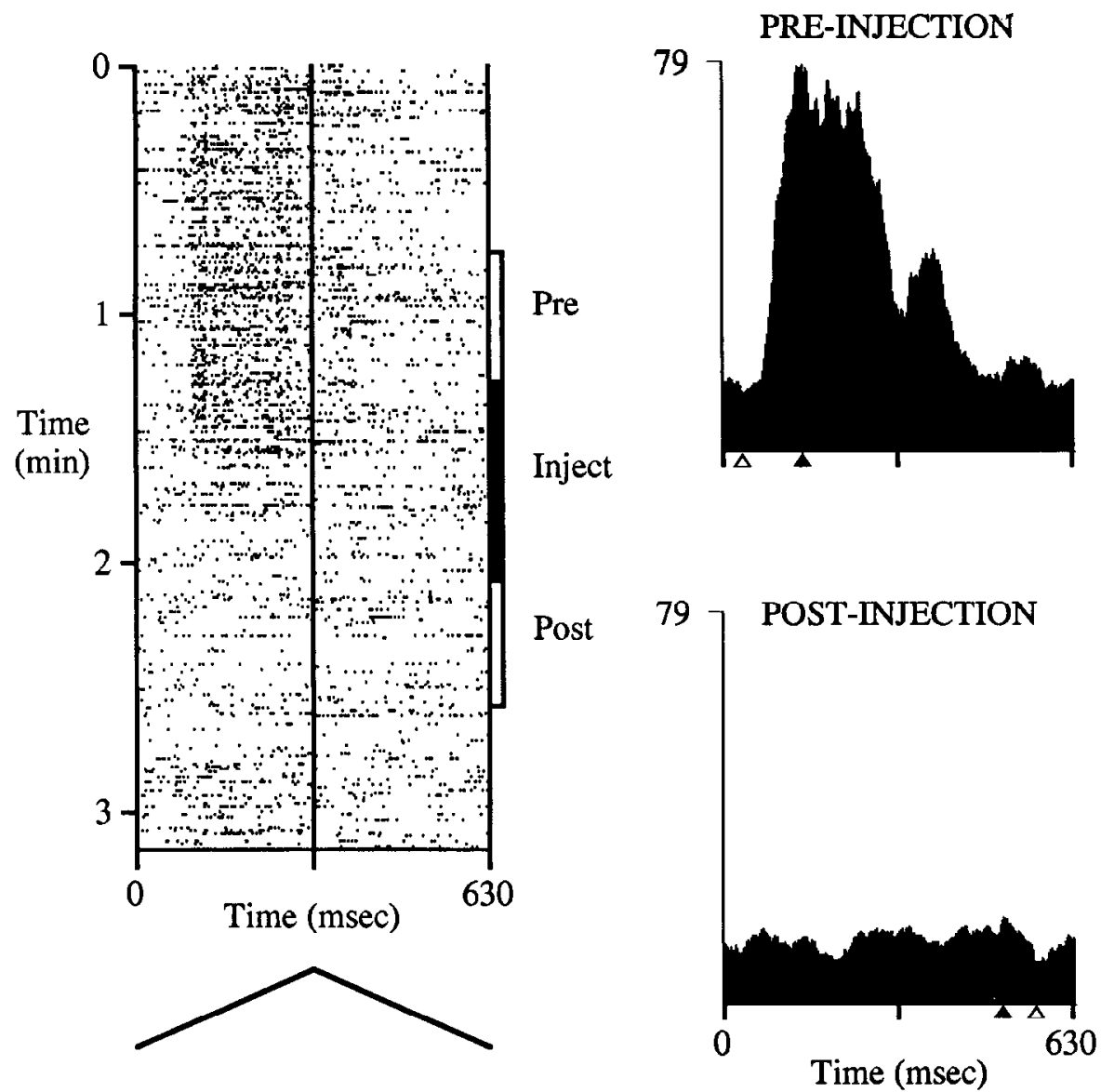

butions to cortical responses, and because $\mathrm{Mg}^{2+}$, unlike lidocaine, does not inactivate axons passing through the region of the injection. However, lidocaine was used in the other 5 hemispheres because the permanent effects of $\mathrm{Mg}^{2+}$ reduce the amount of data that can be collected. The overall consistency of the results obtained with the 2 agents (see Results), and earlier reports suggesting that fibers of passage are not a problem for selective inactivation in the macaque LGN (Schiller et al., 1979), support the idea that both agents are suitable for these experiments.

Visual stimulation and data collection. The effects of LGN inactivation on cortical responses were measured during a period lasting about 1-2 min after an injection was completed. During this time, the effects of the blocking agents were sufficiently restricted that they affected only 1 or 2 layers in the LGN (Fig. 1). The macaque LGN has 6 layers in the region representing the central visual field: layers 1 and 2 are magnocellular, and layers 3 to 6 are parvocellular. To improve the selectivity of the inactivation resulting from LGN injections, only the contralateral eye was stimulated during data collection. As a result, only magnocellular layer 1 and parvocellular layers 4 and 6 were active. Layers 2 and 3 therefore served as a physical buffer between the active magnocellular and parvocellular layers. This allowed us to keep the effects of the injections entirely restricted to one or the other subdivision during the period of data collection. Because most units in the MT respond readily to either eye (Maunsell and Van Essen, 1983a), monocular stimulation did not substantially reduce cortical responses.

The injection probe was positioned near the center of 1 of the 3 active LGN layers before making an injection. The limited spread of inactivation in the LGN meant that only a small portion of the visual field representation could be inactivated within the injected layer. The large receptive fields found in the MT cover regions of the visual field that are too extensive to be inactivated with such LGN injections. However, most neurons in the MT respond well to small targets that flash on and off or move back and forth along a short excursion within a portion of the visual field that can be inactivated by an LGN injection. In these experiments, MT responses were driven with visual stimuli that never traveled more than $2^{\circ}$ from the center of the blocked LGN representation. We located receptive fields in the MT that were centered away from the fovea (average eccentricity, $15^{\circ}$ ), so that corresponding representations in the LGN had moderate to low magnification [e.g., magnification at $15^{\circ}$ in the LGN layer 6 is $\sim 150 \mu \mathrm{m} /{ }^{\circ}$, and in LGN layer 1 , is $\sim 80 \mu \mathrm{m} /{ }^{\circ}$ (Connolly and Van Essen, 1984)]. With this approach, the entire representation of a visual stimulus within an LGN layer could be inactivated with a single injection.

Once receptive fields in the MT and the LGN were suitably aligned and an adequate visual stimulus was found, data were collected while the stimulus was presented under computer control. Flashing stimuli were delivered with a $50 \%$ duty cycle. Moving stimuli swept back and forth across the receptive field in the preferred and null directions at the site's preferred speed. Signals from units or multiunil clusters were digitized using a window discriminator and collected by the computer with a $1-\mathrm{msec}$ resolution. Stimulus presentation was synchronized with the frame rate of the video display, and each stimulus cycle comprised an integer number of display frames. Data were usually collected continuously for at least 2 min before an injection was made and for 10 min afterward. Electrolytic lesions $(10 \mu \mathrm{A}$ for $10 \mathrm{sec})$ were made at selected sites in the cortex to facilitate the subsequent electrode track reconstruction.

Data analysis. Data were analyzed with methods similar to those used in previous studies (Malpeli, 1983). The method of analysis is illustrated in Figure 2, which shows responses from a multiunit site in the MT before, during, and after an 85-nl injection of lidocaine into magnocellular layer 1. For each LGN block, a pre- and a postinjection cortical response were calculated by constructing average response histograms from the 50 stimulus cycles immediately preceding and immediately following the LGN injection (Fig. 2, left panel). Smoothed versions of these histograms (Fig. 2, right panels) were made by performing running averages with an averaging length equal to $1 / 10$ of the stimulus period. In order to include both excitatory and inhibitory modulation of activity, we based response on the difference between the peak and trough in each smoothed histogram (solid and open triangles). 
MAGNOCELLULAR BLOCKS

A: BI 0.59
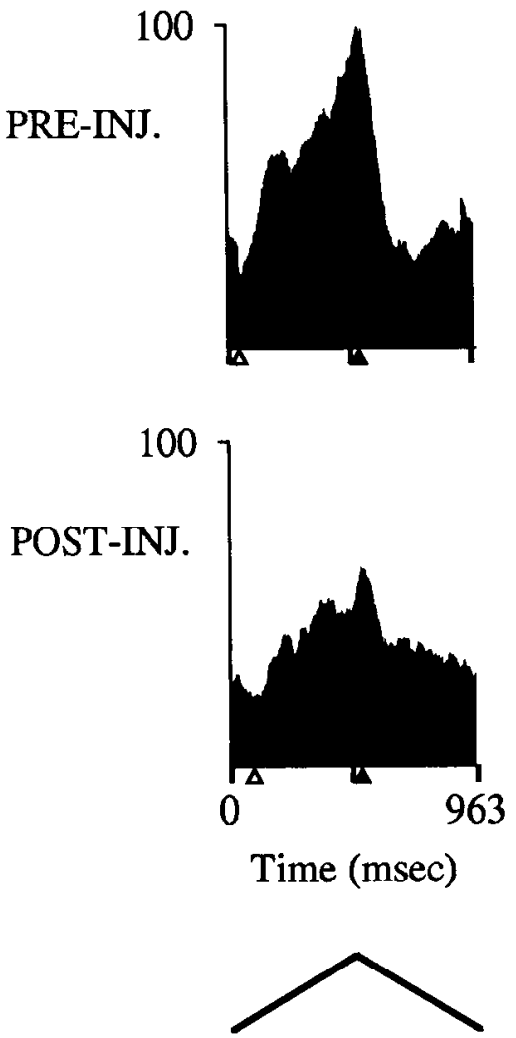

B: BI 0.72

58

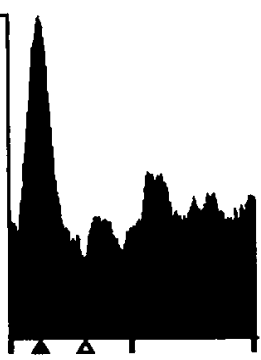

58

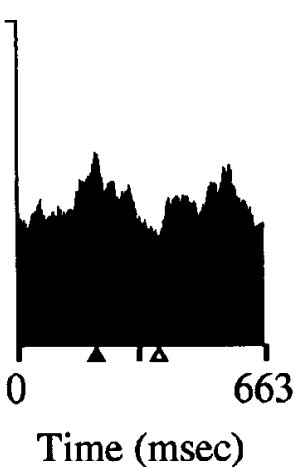

59

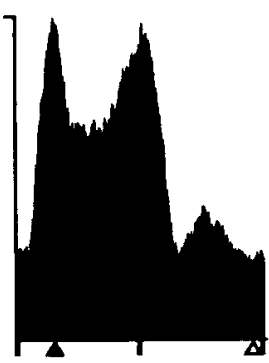

59
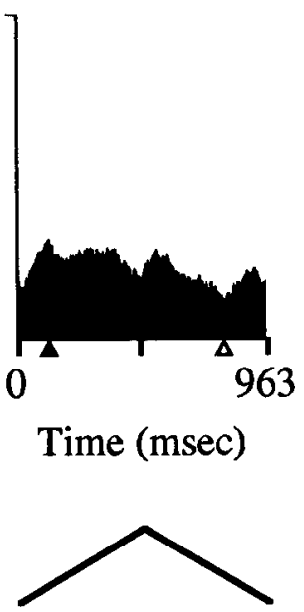

Figure 3. Representative effects of magnocellular blocks for 3 multiunit MT sites. Each pair of histograms shows responses before and after blocking LGN layer 1 and were prepared as described for Figure 2. The blocking indices $(B I)$ for these sites are approximately equal to the values for the first, second, and third quartiles of the distribution of magnocellular blocking indices. $A$, Effect of a $150-\mathrm{nl} \mathrm{Mg}^{2+}$ injection. $B$, Effect of a $60-\mathrm{nl} \mathrm{Mg}^{2+}$ injection. $C$, Effect of a 75-nl lidocaine injection. The vertical axes are scaled in spikes/ sec. The lines below the histograms in $A$ and $C$ indicate that the stimuli moved back and forth, and the open and solid bars below the histograms in $B$ indicate that the stimulus was stationary and flashed on and off. . The solid and open triangles indicate peaks and troughs.
Because noise in the histogram increases the difference between the peak and trough, the response was taken to be the difference between the peak and trough minus a baseline peak/trough difference determined from activity sampled in the absence of any stimulus. Because we did not sample background activity for a period as long as 50 stimulus cycles, the baseline was assigned using a statistical approach. About 5 sec of background activity were collected prior to each injection and used to determine an average background probability of firing. Fifty passes were then made through a histogram, incrementing bins with a probability equivalent to the measured probability. The resulting synthesized histogram was then smoothed in the same way as the pre- and postinjection histograms, and the difference between the peak and trough was recorded. This process was repeated until the standard error of the mean of the synthesized peak/trough differences was less than 0.05 times the mean. The mean value was then used as a baseline peak/trough difference.

The overall effect of each injection was described by a blocking index, which was $1.0-$ (postinjection response/preinjection response). A value of 0.0 represents no block, and 1.0 represents a complete block. The converse was true for the blocking index used in previous studies (Schiller et al., 1979; Malpeli et al., 1981; Malpeli, 1983). The current blocking index can exceed 1.0 if the difference between the peak and trough in the postinjection histogram was less than the baseline peak/trough difference. The current blocking index also differs from the index in the other studies in that it uses the preinjection response rather than the average of the preinjection response and the response after recovery from the effects of blockade. Including the postrecovery response is unnecessary for interpreting the effects of blockade, and its use would introduce systematic bias to the blocking index, given the permanent effects of $\mathbf{M g}^{2+}$.
Reconstruction of electrode tracks. At the end of the recording session, the animal was given an overdose of barbiturates and perfused with a PBS rinse $(\mathrm{pH}, 7.4)$, followed by paraformaldehyde fixative. The brain was removed, blocked, and equilibrated with glycerol (Rosene et al., 1986). Blocks were then sectioned at a thickness of $40 \mu \mathrm{m}$. Series of sections were stained for Nissl substance or myelin (Gallyas, 1979). Electrode tracks and electrolytic lesions were marked on enlargements of the histological sections. Each cortical recording site was located based on microdrive readings and distance relative to lesions and cortical borders. Sites were identified as being within the MT based on its distinctive myeloarchitectonics (Van Essen et al., 1981). Electrode penetrations within the LGN were not reconstructed.

\section{Results}

\section{Effects of blocking magnocellular $L G N$}

The most striking result from these experiments was the demonstration of a prominent magnocellular contribution to MT responses. Virtually all of the 57 MT sites tested showed a clear reduction in response when magnocellular inputs were blocked. In most cases responses were essentially eliminated.

Figure 2 shows data recorded from a multiunit site in the MT before, during, and after lidocaine was injected into magnocellular layer 1 . The injection was made during the period marked by the solid bar on the right side of the raster. The MT site responded to 1 direction of stimulus movement (left half of raster) up until the time of injection, at which point the response 

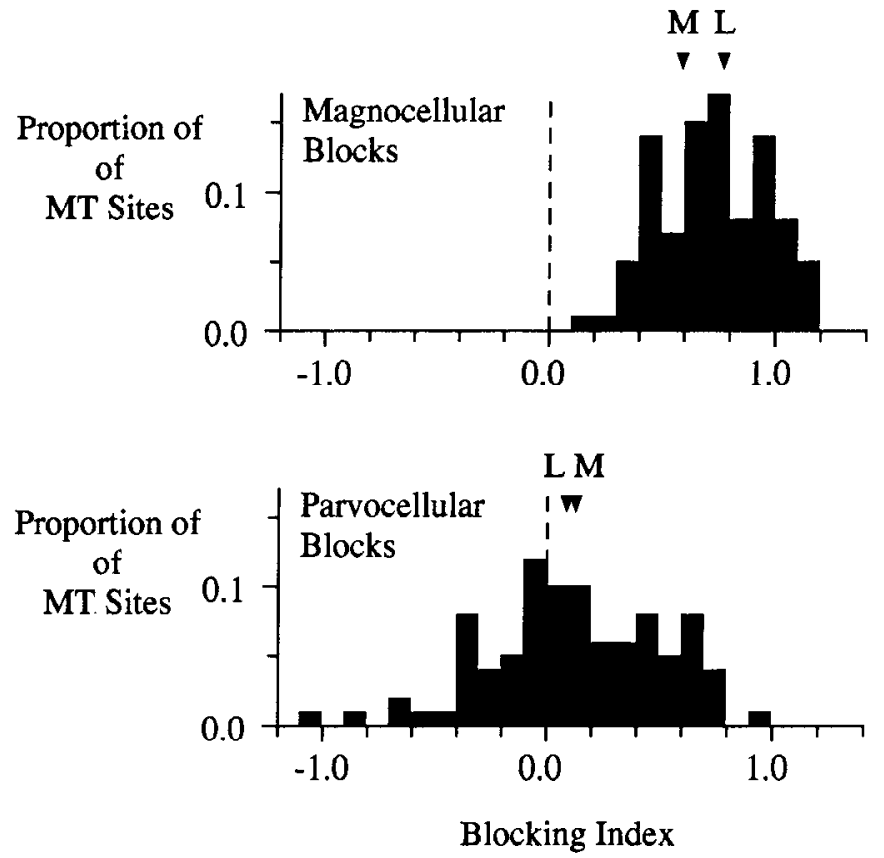

Figure 4. Distribution of magnocellular and parvocellular blocking indices. The upper histogram represents blocking indices resulting from magnocellular injections, and the lower histogram those for parvocellular injections. Magnocellular injections had much greater effects (mean blocking index, 0.72) than parvocellular injections (mean, 0.11). Arrowheads labeled $M$ and $L$ mark the means for $\mathrm{Mg}^{2+}$ and lidocaine injections, respectively. Lidocaine produced slightly stronger blocks for magnocellular injections, but there was no significant difference for parvocellular injections.

was abolished. At this site, like most MT sites, the background level of activity was only slightly affected by the LGN injection. The histograms to the right of the figure show average responses before and after injections. The blocking index for this injection was 1.15 , indicating that the difference between the peak and trough in the postinjection histogram was slightly less than the peak minus trough in the absence of stimulation.

The effects of magnocellular block on responses from 3 other multiunit sites in the MT are illustrated in Figure 3. The preand postinjection histograms were compiled in the same way as those in Figure 2. The cases shown were selected for having blocking indices that represent the range of effects for magnocellular blocks. The blocking index in Figure $3 A$ is close to the first quartile value, Figure $3 B$ is near the median, and Figure $3 C$ is near the third quartile value. For each example, there is an obvious reduction in the MT response following magnocellular block. In Figure 3, $B$ and $C$, there is very little evidence of a response following the magnocellular block. While the effect of the magnocellular block shown in Figure $3 \mathrm{~A}$ is less, the reduction in response is still substantial.

The complete distribution of blocking indices from magnocellular injections is represented in the upper histogram in Figure 4 . Every magnocellular injection reduced responses in the MT (values $>0$ ). The mean value for the magnocellular blocking indices was 0.72 , a value that corresponds to a very large reduction in response (Fig. 3). An alternate way of viewing the overall effects of magnocellular blocks is shown in the upper panel of Figure 5. This plot illustrates the average level of MT response as a function of time before and after magnocellular

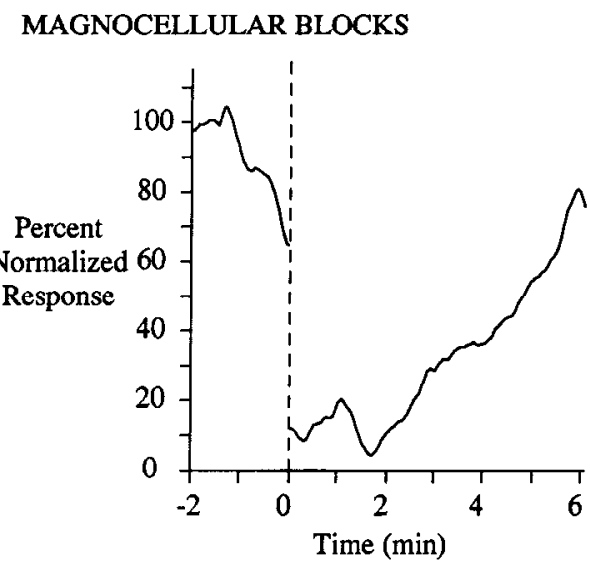

\section{PARVOCELLULAR BLOCKS}

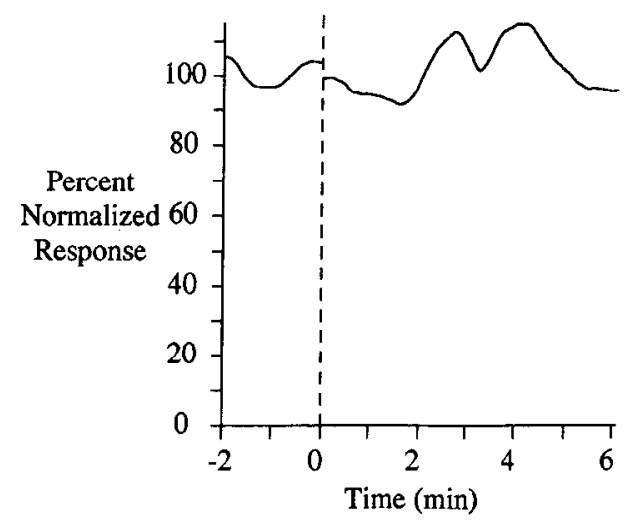

Figure 5. Average effects of magnocellular and parvocellular blocks as a function of time. Each panel shows the average of MT responses for $2 \mathrm{~min}$ before the start of injections (vertical broken line) and $6 \mathrm{~min}$ after their completion. For each MT site, responses were computed for each stimulus presentation. The response to a particular presentation was calculated using 50 sequential stimulus presentations centered on the presentation of interest. These 50 presentations were used to construct an average response histogram from which a response was computed as described in Materials and Methods. Responses were then normalized to the average response during a 1 -min period starting 2 min before injection. Responses from different injections were then compiled into an average with 2 -sec bins. The resulting curves were finally smoothed with a running average of 15 bins. Magnocellular injections had immediate and pronounced effects on MT responses. In contrast, parvocellular blocks produced no clear effect. The magnocellular curve dips before $0 \mathrm{~min}$ because the range of response averaging extended into the injection period for presentations immediately before the injection.

injections. For each of the 57 magnocellular injections, responses were computed as a function of time. Each response sequence was then normalized to the average level of response before the injection, and all the normalized sequences were then averaged. The period during which the injection was made (typically about $10 \mathrm{sec}$ ) was deleted from each curve, so that the plot shows time before the start of the injection and time after the completion of the injection, separated by a vertical dashed line. The plot shows that removing magnocellular input to the MT had a very strong effect on its responses, lowering the overall level of response to a small fraction of its preblocked level.

There was no tendency for larger magnocellular injections to produce larger blocking indices over the range of volumes tested (25-250 nl; correlation coefficient, 0.07), supporting the idea 
PARVOCELLULAR BLOCKS
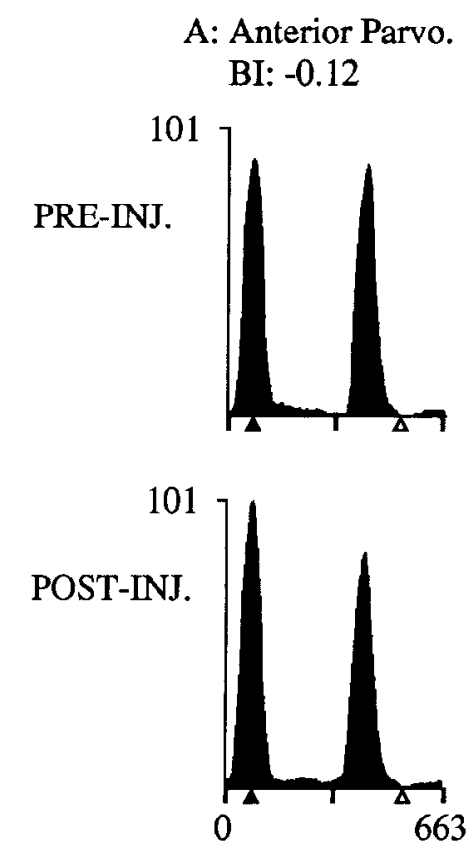

Time (msec)

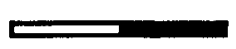

B: Anterior Parvo. BI: 0.13

179

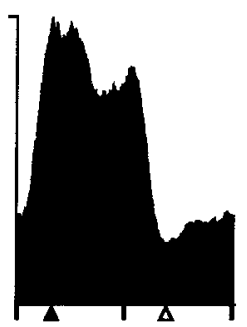

179

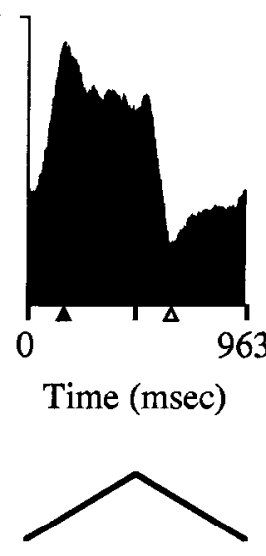

C: Layer 4

BI: 0.40

35

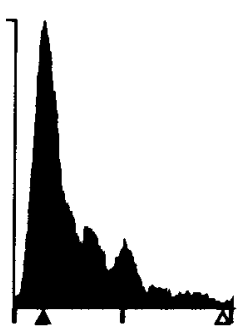

35

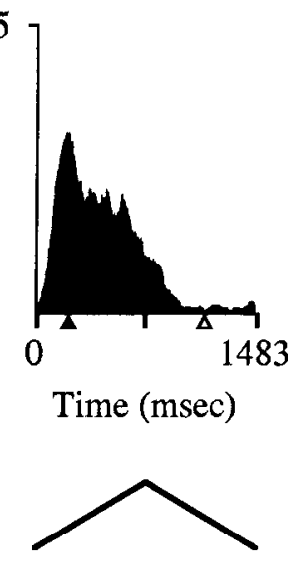

Figure 6. Representative parvocellular blocks from 3 multiunit MT sites. Each pair of histograms shows MT responses before and after block of a parvocellular LGN layer. The blocking indices shown are approximately equivalent to the values of the first, second, and third quartiles of the distribution of parvocellular indices. $A, 175$ $\mathrm{nl}$ lidocaine injection in the anterior parvocellular LGN (where only 1 parvocellular layer was active). $B, 40-n l$ lidocaine injection in the anterior parvocellular LGN. C, 200-nl lidocaine injection in layer 4 . The vertical axes are scaled in spikes/sec. The lines below $A$ and below $B$ and $C$ indicate the stimuli flashed off and on and moved back and forth, respectively. The solid and open triangles indicate peaks and troughs. that all injections were effective in blocking the entire representation of the visual stimulus. Magnocellular injections of lidocaine were significantly more effective at reducing MT responses (average blocking index, $0.78 \pm 0.25 \mathrm{SD} ; n=38$ ) than were $\mathrm{Mg}^{2+}$ injections (average blocking index, $0.59 \pm 0.16 ; n=$ 19). The mean values are marked with arrowheads above the histogram in Figure 4. This difference may result from lidocaine blocking some parvocellular fibers of passage, or it may reflect differences in the action of the 2 agents over space and time (Fig. 1). Because the difference between lidocaine and $\mathrm{Mg}^{2+}$ was relatively small and does not affect any of the conclusions drawn from this study, data from both have been combined in the analysis. More pronounced effects of magnocellular block were also seen for isolated MT units (average blocking index, 0.86; $n=12$ ) than for multiunit sites (average blocking index, 0.68; $n=45$ ). However, this difference can be attributed to our use of lidocaine as the blocking agent at 11 of the 12 single unit sites.

\section{Effects of blocking parvocellular $L G N$}

Parvocellular block usually did not have pronounced effects on responses in the MT. The distribution of parvocellular blocking indices in the lower half of Figure 4 has a mean of only 0.11 . Much of the width in the distribution probably arises from random fluctuations in MT responses. The plot in the lower panel of Figure 5 shows that on average, there was no clear change in MT responsiveness following parvocellular injections.

Responses before and after parvocellular injections from 3 different sites in the MT are shown in Figure 6. As in Figure 3, the blocking indices are close to the first, second, and third quartile values. Parvocellular injections usually failed to produce a clear reduction in MT responses and rarely had a strong effect. For parvocellular injections, no significant difference existed between the blocking indices computed for single-unit sites (17) and multiunit sites (58), or between effects from lidocaine (45 sites) or $\mathrm{Mg}^{2+}$ (30 sites) injections (2-tailed $t$ test, $p>0.05$ ). There was also no clear tendency for larger parvocellular injections to be associated with larger blocking index values (correlation coefficient, 0.22 ).

With the contralateral visual stimulation that was used for all data collection, 2 parvocellular layers are active as opposed to 1 active magnocellular layer. Only 1 parvocellular layer was blocked by each injection. This raises the question of whether the failure to produce strong effects with parvocellular injections might arise from failing to block transmission through one of the parvocellular layers when injecting the other. This was not the case. The macaque LGN has 6 layers only in the posterior part of the nucleus, which represents the central visual hemifield (Kaas et al., 1972). As one moves more anterior in the nucleus, the 4 parvocellular layers condense into 2 , with the transition occurring at the representation of about $17^{\circ}$ eccentricity (Malpeli and Baker, 1975). In the anterior LGN, only a single parvocellular layer is driven by the contralateral eye, and in this region it is possible to make parvocellular blocks that are directly comparable to magnocellular blocks.

Almost $1 / 2$ of the parvocellular blocks $(35 / 75)$ were made in the anterior, 4-layered part of the LGN. The histograms in Figure 6, $A$ and $B$, were taken from anterior parvocellular blocks. The results from injections made in the anterior LGN were not significantly different from those in the 6-layered part of the 
A: BI 0.48
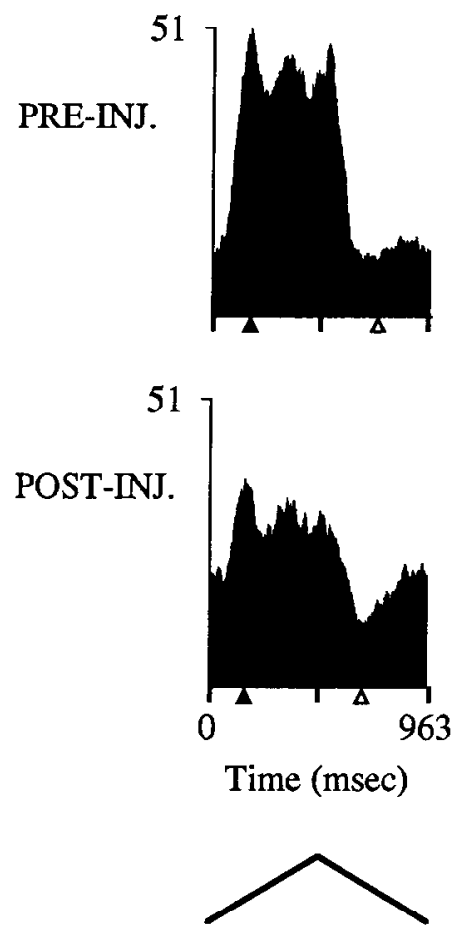

B: BI 0.54

48

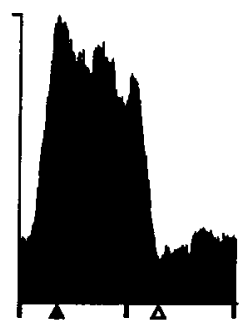

48
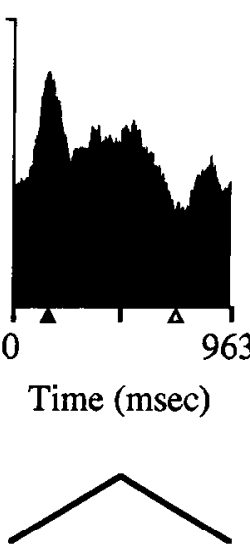

C: BI 0.41

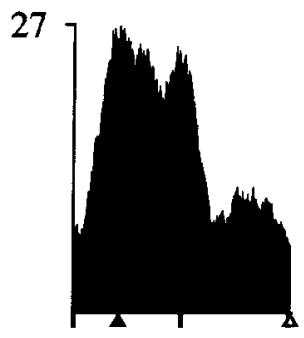

27

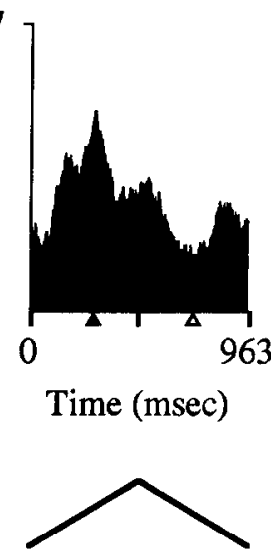

- Anterior Parvo. Block

- Layer 6 Parvo. Block

- Layer 4 Parvo. Block

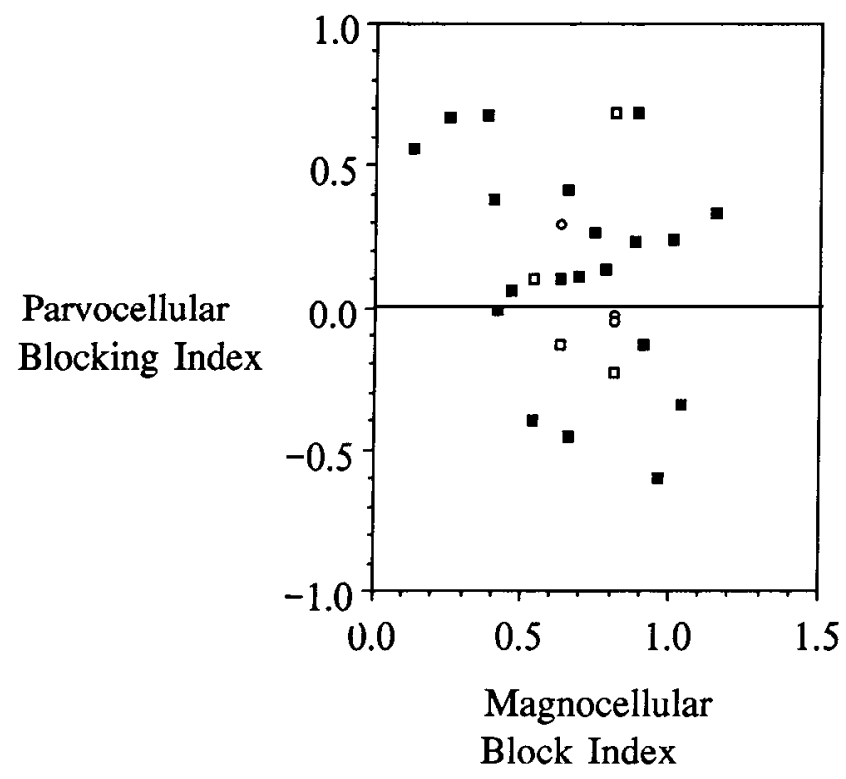

Figure 8. Relationship between magnocellular and parvocellular blocking indices for individual MT sites. Blocking indices are plotted for all MT sites that were tested with both parvocellular and magnocellular blocks. Open symbols represent parvocellular injections made in the 6-layered part of the LGN. Little systematic relationship exists between the 2 types of contributions. Three MT sites were tested with injections of layers 1,4 , and 6 . Two points are associated with each of these sites: the 3 open circles marking the layer-4 blocks and the open squares that are vertically aligned with them.
LGN (mean blocking index 0.09 vs 0.13 ), demonstrating that the difference between magnocellular and parvocellular injections did not stem from incomplete blocks of parvocellular signals.

\section{Parvocellular contributions to $M T$ responses}

Although MT activity largely depends on magnocellular inputs, responses were clearly reduced after some parvocellular injections. Because parvocellular effects were not common and were generally weak, additional experiments were completed to demonstrate that they were genuine. Because parvocellular effects on the MT were found with both lidocaine and $\mathrm{Mg}^{2+}$, they cannot be attributed to block of axons from magnocellular neurons that pass through the injected region. However, we wished to address the question of whether the reduction in the MT response seen for some parvocellular injections might arise either from random fluctuations in cortical responsiveness or from the spread of the blocking agent to the magnocellular LGN.

The consistency of parvocellular blocks was demonstrated by making repeated injections at individual sites. Figure 7 depicts data collected from an MT multiunit site during repeated parvocellular injections. A total of 4 injections were made in the course of $3 \mathrm{hr}$. In every case, the block reduced but did not eliminate the MT response. Although the volume injected ranged from 50 to $125 \mathrm{nl}$ and the absolute level of response varied during this period, the effects of parvocellular blocks were dependable and consistent (blocking indices: $0.48,0.54,0.41,0.57$ ), effectively ruling out the possibility that the reduced responses were due to random fluctuations in MT responsiveness.

To show that the effects of parvocellular injections did not arise from unexpected spread of the blocking agent into the magnocellular layers, during 8 parvocellular injections we used a second probe to record responses from the corresponding rep- 
A: Magno. Layer 1 BI: 0.81
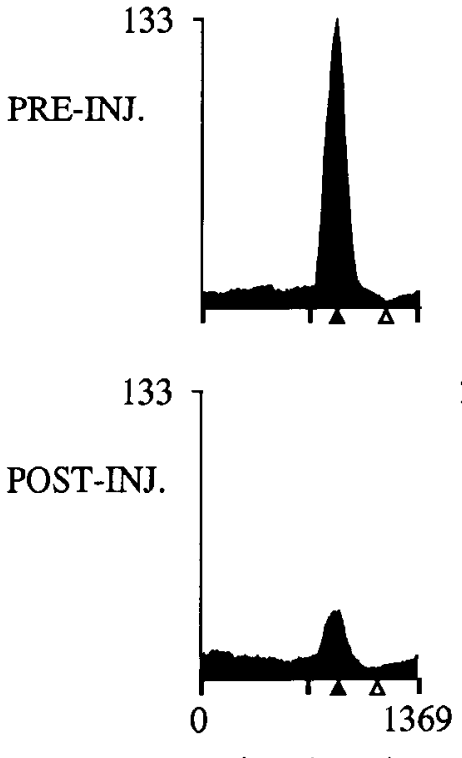

Time (msec)

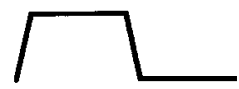

B: Parvo. Layer 4 BI: -0.05

229

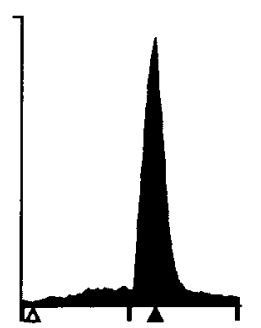

229
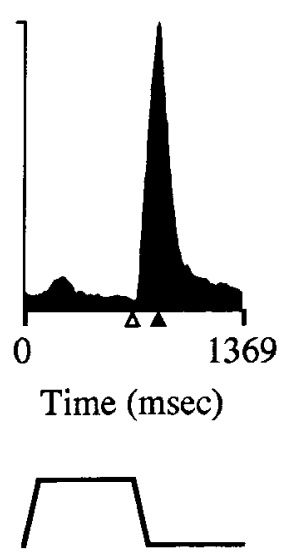

C: Parvo. Layer 6 BI: 0.69

164

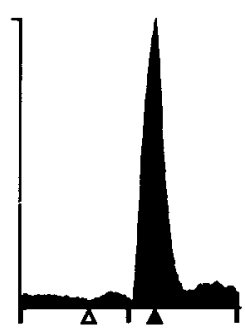

164

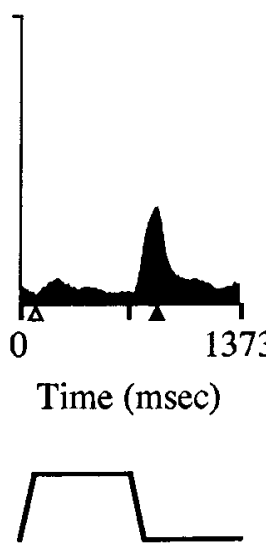

Figure 9. Changes in responses at an MT site following individual blocks of layers 1,4 , and 6 . The trapezoidal profiles below each pair of histograms indicate that each movement of the stimulus was followed by a pause, during which it was stationary. Seventy-five nanoliters of lidocaine were injected in each LGN layer. Blocking either layer 1 or layer 6 reduced MT responses, but the block of layer 4 had no clear effect. The vertical axes are scaled in spikes/ sec. The solid and open triangles indicate peaks and troughs, respectively. resentation in LGN layer 1 at the same time that the MT data wcre being collected. The magnocellular responses were unaffected by the parvocellular injections. The blocking indices for the magnocellular responses collected before and after the parvocellular injections averaged $-0.10 \pm 0.08$ (SE). The difference between this value and 0.00 is not statistically significant (2tailed $t$ test, $p>0.1$ ). Therefore, the effects of the injections were restricted to the parvocellular subdivision. Further evidence that parvocellular effects were not due to the blocking agent spreading to the magnocellular subdivision was provided by an MT site for which a layer-6 injection reduced responses, but an injection of layer 4 (which is closer to the magnocellular subdivision) did not (see Fig. 9).

\section{Magnocellular and parvocellular contributions to individual sites}

We were interested in determining the relative strengths of $\mathbf{P}$ and $M$ channcl contributions to individual sites in the MT. In particular, we wanted to determine whether sites with more pronounced $P$ channel input had weaker $M$ channel input. Twenty-four MT sites were tested for both magnocellular and parvocellular contributions. For 13 of these, 2 recording/injection probes were positioned in the LGN in corresponding representations in layer 1 and the anterior parvocellular layer. For the remaining tests, a single probe was moved from layer to layer between injections. Figure 8 shows the relationship between the magnocellular and parvocellular contributions to responses of MT sites. Open symbols indicate posterior parvocellular blocks where 1 parvocellular layer remained active. As expected, magnocellular blocking indices were generally larger than parvocellular indices. The 3 or 4 sites with the smallest magnocellular blocking indices (Fig. 8, upper left) were among those with the largest parvocellular blocking indices, but the overall correlation between the values was very weak (correlation coefficient, -0.30 ).

Only 3 of these MT sites involved tests of both layer-4 and layer-6 parvocellular blocks. Nevertheless, 1 case showed that layer- 4 and layer- 6 contributions can differ greatly. Figure 9 shows responses at an MT site before and after layers 1,4 , and 6 were blocked individually. The layer- 6 injection was distinctive in producing one of the most pronounced reductions of MT response for a parvocellular block (see Fig. 8). The magnocellular block also greatly affected MT responses. However, a layer-4 injection at the corresponding representation failed to have any pronounced effect.

When 2 recording/injection probes were aligned in the LGN, it was possible to inactivate all LGN contributions by making paired injections into the anterior parvocellular LGN and the corresponding representation in layer 1 . This was done for 3 MT sites, and the results are shown in Figure 10, in which each column represents data from a different MT site. In each case, the paired LGN injections left no clear MT response, as can be seen in the second row of histograms. The effects of the magnocellular and parvocellular blocks made individually are shown in the lowest 2 rows. In each case, the effects of the combined injections were greater than those for single injections.

\section{Discussion}

These results show that the magnocellular layers of the LGN are a major contributor to responses in the MT, in contrast to the parvocellular layers, which provide a much smaller component. This differential input provides strong support for the suggestion that the $\mathrm{M}$ and $\mathbf{P}$ channels remain appreciably segregated in extrastriate visual cortex.

The details of the test conditions must be taken into account in interpreting the results. One consideration is that all mea- 
Figure 10. Effects of complete LGN blocks. Each column represents data from 1 of the 3 MT sites where injections were made in layer 1 and the anterior parvocellular simultaneously. The second row shows responses recorded immediately after the paired injections. Blocking all LGN transmission eliminated identifiable responses in the MT. The third and fourth rows show the responses of the same MT sites following magnocellular and parvocellular blocks performed individually. The combined blocks appeared to be more potent than any single injection. The preinjection histograms were taken from responses collected immediately before the paired injections. The height of each histogram in the lowest 2 rows has been normalized to the level of response recorded immediately before the corresponding injection was made. The vertical axes are scaled in spikes/sec. The lines below the histograms indicate the stimuli consisted of movement back and forth. The solid and open triangles indicate peaks and troughs.

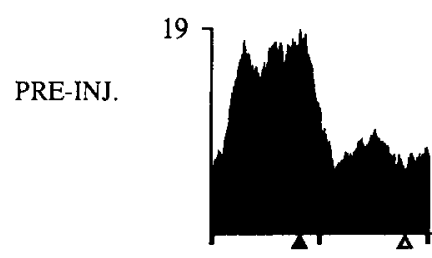

PAIRED
BLOCK

B:

189

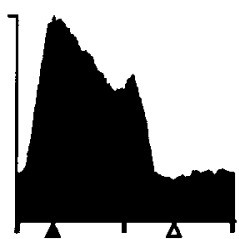

19
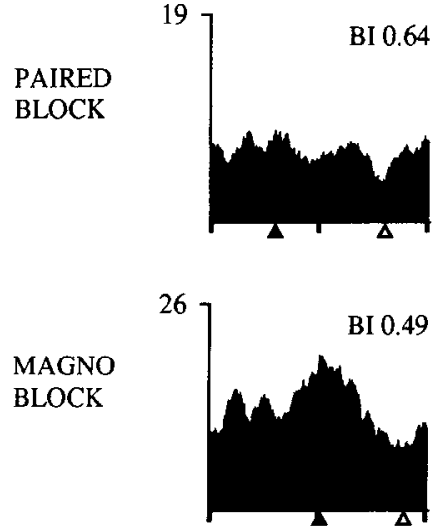

PARVO

BLOCK

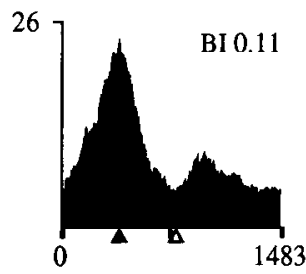

Time (msec)

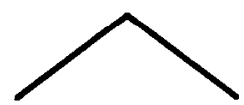

189

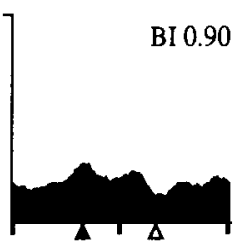

191

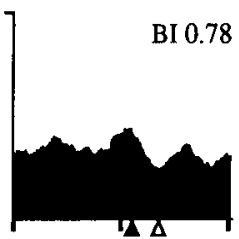

179
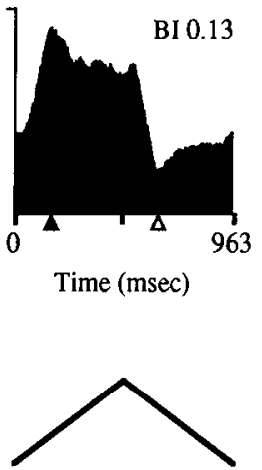

C.
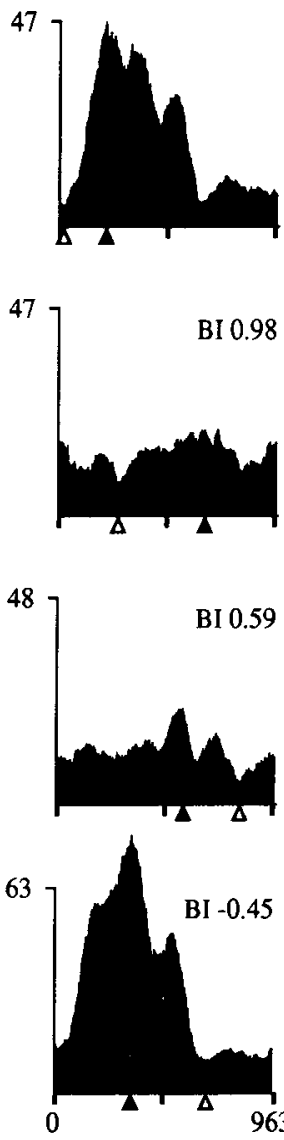

Time (msec)

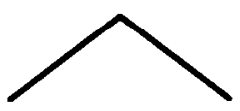

surements were made using stimuli whose direction and speed had been optimized for the MT site in question. Although parvocellular contributions were not pronounced using such stimuli, it remains possible that parvocellular inputs could make other contributions, such as determining the sharpness of tuning for direction or in providing for responses to near-threshold stimuli. Contributions such as these would not be detected in the current study. Another consideration is that the stimuli were optimized within constraints and so were generally not completely optimal: Stimuli were necessarily prohibited from making large excursions, which generally produce the largest responses from MT neurons. While most MT sites responded well nevertheless, it is again possible that parvocellular inputs might be more apparent if the experiments could have been performed using larger excursions. It is also possible that the $P$ channel preferentially contributes to those sites that failed to respond well to small stimulus excursions and were consequently not tested. While we do not believe that any of these possibilities is likely, they cannot be ruled out by these data.

Two laboratories have examined responses in the MT while inactivating V1. Rodman et al. (1989) and Bullier and Girard (1988) both found that some neurons in the MT retain some level of responsivity when $\mathrm{Vl}$ is inactivated. Very few LGN neurons project to cortical targets other than V1 (Benevento and Yoshida, 1981; Yukie and Iwai, 1981), and these projections avoid the MT (Benevento and Standage, 1982). It is therefore likely that the remaining responses are mediated via thalamic structures such as the pulvinar (see Rodman et al., 1989). In the current study, no obvious responses were seen when LGN transmission was completely blocked (Fig. 10). However, only 3 sites were tested in this way, and it is possible that responses might be found if more sites were tested, or if larger stimuli and larger excursions could have been used.

Although the $\mathrm{P}$ channel input to the MT was relatively minor, an unequivocal contribution could be demonstrated for some sites. This input might represent unwanted cross-talk between the $P$ and $M$ channels in the cortex, but it is possible that it plays an important functional role. Although most interpretations emphasize the concurrent nature of processing in the different cortical streams, interactions between different pathways may contribute, as well (see DeYoe and Van Essen, 1988). For example, some movements can only be seen if color or texture borders are first detected. Conversely, in some cluttered environments, the structure of an object may be discernible only by 
its motion relative to the background. Tasks that rely on several types of visual information may depend on direct communication between the motion and the color and form pathways. Some MT neurons respond to stimuli in which detection of motion requires color or form analysis (Albright, 1987; Saito et al., 1989). We suspect that these neurons may correspond to those receiving parvocellular inputs, and we hope to examine this possibility in the near future.

While the current study provides support for the association between the $M$ channel and the motion pathway, further experiments will be needed before the extent of $P$ and $M$ channel intermixing in the extrastriate cortex will be understood. The $P$ and $\mathbf{M}$ channel contributions to the color and form pathway remain to be established. Several studies have suggested that magnocellular input may enter the color and form pathway at the level of V1 (see Livingstone and Hubel, 1987a; DeYoe and Van Essen, 1988). Thus, the $P$ channel may not dominate the color and form pathway to the same extent that the $\mathrm{M}$ channel dominates the motion pathway up to the level of the MT. In addition, the $M$ and $P$ channel contributions to the later stages of the motion pathway also need to be examined. While the parvocellular contributions to the MT may represent a small but necessary bridge between the pathways, they could equally well reflect an early stage of intermixing that is completed when the time signals reach the highest levels of the visual cortex.

While many questions remain about the fate of the $P$ and $M$ channels in the cortex, the results reported here support the idea that they remain largely segregated and contribute differentially to the motion pathway. If future investigations confirm strong associations between the $\mathrm{M}$ channel and the motion pathway and between the $P$ channel and the color and form pathway, the pattern of organization would have several important consequences. If the $P$ and $M$ channels remain separated up to the parietal and inferotemporal cortex and are important for determining the neurophysiological differences between these regions, then the retinocortical visual system in primates could be considered to contain 2 subsystems that operate largely in parallel from the level of the retina through to the highest cortical stages. In this framework, the well-characterized differences between M-channel and P-channel retinal ganglion cells appear to be specializations for the analysis of motion on the one hand and object indentity on the other. For example, the short latency, transient responses of $\mathrm{M}$ cells may provide temporal resolution needed for accurate assessment of direction and speed of movement. The color sensitivity and higher spatial resolution of $\mathrm{P}$ cells may be unnecessary or even an impediment for the analysis of trajectories of well-delineated objects. On the other hand, such sensitivities are well suited to evaluating surface details such as textures or outline, which may be essential to object identification.

\section{References}

Albright TD (1987) Isoluminant motion processing in macaque visual area MT. Soc Neurosci Abstr 13:1626.

Benevento LA, Standage GP (1982) Demonstration of lack of dorsal lateral geniculate input to extrastriate areas MT and visual area 2 in the macaque monkey. Brain Res 252:161-166.

Benevento LA, Yoshida K (1981) The afferent and efferent organization of the lateral geniculo-prestriate pathways in the macaque monkey. J Comp Neurol 203:455-474.

Berson DM (1985) Cat lateral suprasylvian cortex: Y-cell inputs and corticotectal projection. J Neurophysiol 53:544-556.

Bullier J, Girard P (1988) Visual responses of neurons in area V2 and in the superior temporal sulcus of the macaque monkey during reversible inactivation of area V1. Soc Neurosci Abstr 14:602.

Burkhalter A, Felleman DJ, Newsome WT, Van Essen DC (1986) Anatomical and physiological asymmetries related to visual areas V3 and VP in macaque extrastriate cortex. Vision Res 26:63-80.

Connolly M, Van Essen D (1984) The representation of the visual field in parvicellular and magnocellular layers of the lateral geniculate nucleus in the macaque monkey. J Comp Neurol 226:544-564.

Derrington AM, Lennie P (1984) Spatial and temporal contrast sensitivities of neurons in lateral geniculate nucleus of macaque.J Physiol (Lond) 357:291-240.

Desimone R, Schein SJ, Moran J, Ungerleider LG (1985) Contour, color and shape analysis beyond the striate cortex. Vision Res 25: $441-452$.

DeYoe EA, Van Essen DC (1985) Scgregation of efferent connections and receptive field properties in visual area $\mathrm{V} 2$ of the macaque. Nature $317: 58-61$.

DeYoe EA, Van Essen DC (1988) Concurrent processing streams in monkey visual cortex. Trends Neurosci 11:219-226.

Dodge FA, Rahamimoff R (1967) Co-operative action of calcium ions in tramsmitter release at the neuromuscular junction. J Physiol (Lond) 193:419-432.

Gallyas F (1979) Silver staining of myelin by means of physical development. Neurol Res 1:203-209.

Graham J (1982) Some topographical connections of the striate cortex with subcortical structures in Macaca fascicularis. Exp Brain Res 47: $1-14$.

Graham J, Lin C, Kaas JH (1979) Subcortical projections of six visual cortical areas in the owl monkey, Aotus trivirgatus. J Comp Neurol 187:557-580.

Hendrickson AE (1985) Dots, stripes and columns in monkey visual cortex. Trends Neurosci 8:406-410.

Hille B (1972) The permeability of the sodium channel to metal cations in myelinated nerve. J Gen Physiol 59:637-658.

Hubel DH, Wiesel TN (1972) Laminar and columnar distribution of geniculo-cortical fibers in macaque monkeys. J Comp Neurol 146: $421-450$.

Kaas JH, Guillery RW, Allman JM (1972) Some principles of organization in the dorsal lateral geniculate nucleus. Brain Behav Evol 6 : 253-299.

Lennie P (1980) Parallel visual pathways: a review. Vision Res 20: 561-594.

Livingstone MS, Hubel DH (1987a) Psychophysical evidence for separate channels for the perception of form, color, movement, and depth. J Neurophysiol 7:3416-3468.

Livingstone MS, Hubel DH (1987b) Connections between layer 4B of area 17 and thick cytochrome oxidase stripes of area 18 in squirrel monkey. J Neurosci 7:3371-3377.

Livingstone, MS, Hubel DH (1988) Segregation of form, color, movement, and depth: anatomy, physiology, and perception. Science 240 740-749.

Lund JS, Boothe RG (1975) Interlaminar connections and pyramidal neuron organisation in the visual cortex, area 17, of the macaque monkey. J Comp Neurol 159:305-334.

Lund JS, Lund RD, Hendrickson AE, Bunt AH, Fuchs AF (1976) The origin of efferent pathways from the primary visual cortex area 17 , of the macaque monkey as shown by retrograde transport of horseradish peroxidase. J Comp Neurol 164:287-304.

Malpeli JG (1983) Activity of cells in area 17 of the cat in absence of input from layer A of lateral geniculate nucleus. J Neurophysiol 49 595-610.

Malpeli JG, Baker FH (1975) The representation of the visual field in the lateral geniculate nucleus of Macaca mulatta. J Comp Neurol 161:569-594.

Malpeli JG, Schiller PH (1979) A method of reversible inactivation of small regions of brain tissue. J Neurosci Meth 1:143-157.

Malpeli JG, Schiller PH, Colby CL (1981) Response properties of single cells in monkey striate cortex during reversible inactivation of individual lateral geniculate laminae. J Neurophysiol 46:1102-1119.

Maunsell JHR (1987) Physiological evidence for two visual subsystems. In: Matters of intelligence (Vaina LM, ed), pp. 59-87. Dordrecht, Holland: D. Reidel.

Maunsell JHR, Newsome WT (1987) Visual processing in monkey extrastriate cortex. Ann Kev Neurosci 10:363-401.

Maunsell JHR, Schiller PH (1984) Evidence for the segregation of 
parvo- and magnocellular channels in the visual cortex of the macaque monkey. Soc Neurosci Abstr 10:520.

Maunsell JHR, Van Essen DC (1983a) Functional properties of neurons in the middle temporal visual area of the macaque: I. Selectivity for stimulus direction, speed, and orientation. J Neurophysiol 49: $1127-1147$

Maunsell JHR, Van Essen DC (1983b) The connections of the middle temporal visual area in the macaque and its relationship to a hierarchy of cortical visual areas. J Neurosci 3:2563-2586.

Maunsell JHR, DePriest DD, Nealey TA (1989) The middle temporal visual area receives excitatory drive primarily via the magnocellular layers of the LGN. Invest Ophthalmol Vis Sci 30:427.

Merigan WH, Byrne CE, Maunsell JHR (1989a) Role of the magnocellular pathway in primate vision. Soc Neurosci Abstr 15:1256.

Merigan WH, Katz LM, Maunsell JHR (1989b) Contribution of the primate parvocellular pathway to acuity and contrast sensitivity. Invest Ophthalmol Vis Sci 30:53.

Mishkin M, Ungerleider LG, Macko KA (1983) Object vision and spatial vision: two cortical pathways. Trends Neurosci 6:414-417.

Nealey TA, DePriest DD, Maunsell JHR (1989) Magnocellular and parvocellular contributions to area MT in macaque extrastriate cortex. Soc Neurosci Abstr 15:161.

Petersen SE, Miezin FM, Allman JM (1988) Transient and sustained responses in four extrastriate visual areas of the owl monkey. Exp Brain Res 70:55-60.

Robinson DL, Goldberg ME, Stanton GB (1978) Parietal association cortex in the primate: sensory mechanisms and behavioral modulations. J Neurophysiol 41:910-932.

Rodman HR, Gross CG, Albright TD (1989) Afferent basis of visual response properties in area MT of the macaque. I. Effects of striate cortex removal. J Neurosci 9:2033-2050.

Rosene DL, Roy NJ, Davis BJ (1986) A cryoprotection method that facilitates cutting frozen sections of whole monkey brains for histological and histochemical processing without freezing artifact. J Histochem Cytochem 34:1301-1315.

Saito H, Tanaka K, Isono H, Yasuda M, Mikami A (1989) Directionally selective response of cells in the middle temporal area (MT) of the macaque monkey to the movement of equiluminous opponent color stimuli. Exp Brain Res 75:1-14.

Schiller, P, Logothetis N, Charles E (1990) Functions of the colouropponent and broad-band channels of the visual system. Nature 343: 68-70.

Schiller PH, Malpeli JG (1978) Functional specificity of lateral geniculate nucleus laminae of the rhesus monkey. J Neurophysiol 41:788797.
Schiller PH, Malpeli JG, Schein SJ (1979) Composition of geniculostriate input to superior colliculus of the rhesus monkey. J Neurophysiol 42:1124-1133.

Sclar G, Lennie P, Maunsell JHR (1990) Coding of image contrast in central visual pathways of the macaque monkey. Vision Res 30:110.

Shapley RM, Kaplan E (1986) What are the P and M cells of the monkey visual system sensitive to? Soc Neurosci Abstr 12:7.

Shipp S, Zeki \$ (1985) Segregation of pathways leading from area V2 to areas V4 and V5 of macaque monkey visual cortex. Nature 315: 322-325.

Stone J (1983) Parallel processing in the visual system: the classification of retinal ganglion cells and its impact on the neurobiology of vision. New York: Plenum.

Tigges J, Tigges M, Cross NA, McBride RL, Letbetter WD, Anschel S (1982) Subcortical structures projecting to visual cortical areas in squirrel monkey. J Comp Neurol 209:29-40.

Ungerleider LG, Mishkin M (1982) Two cortical visual systems. In: Analysis of visual behavior (Ingle DJ, Goodale MA, Mansfield RJW, eds), pp 549-585. Cambridge, MA: MIT.

Ungerleider LG, Desimone R, Galkin TW, Mishkin M (1984) Subcortical projections of area MT in the macaque. J Comp Neurol 223: 368-386.

Van Essen DC (1985) Functional organization of primate visual cortex. In: Cerebral cortex (Peters A, Jones EG, eds), pp 259-329. New York:Plenum.

Van Essen DC, Maunsell JHR (1983) Hierarchical organization and functional streams in the visual cortex. Trends Neurosci 6:370-375.

Van Essen DC, Maunsell JHR, Bixby JL (1981) The middle temporal visual area in the macaque: myeloarchitecture, connections, functional properties and topographic organization. J Comp Neurol 199: 293-326.

Wong-Riley M, Carroll EW (1984) Effect of impulse blockage on cytochrome oxidase activity in monkey visual system. Nature 307:262264.

Yukie M, Iwai E (1981) Direct projection from the dorsal lateral geniculate nucleus to the prestriate cortex in macaque monkeys. J Comp Neurol 201:81-97.

Zeki SM (1974) Functional organization of a visual area in the posterior bank of the superior temporal sulcus of the rhesus monkey. $J$ Physiol (Lond) 236:549-573.

Zeki SM (1977) Colour coding in the superior temporal sulcus of rhesus monkey visual cortex. Proc R Soc Lond [Biol] 197:195-223. 